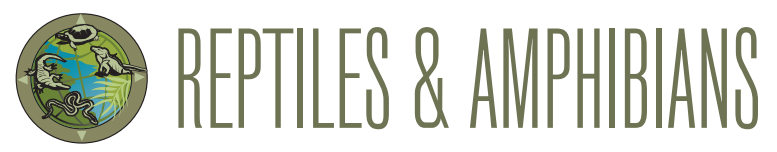

\title{
Predation by an Ornate Flying Snake, Chrysopelea ornata (Colubridae), on an Indian Bark Gecko, Hemidactylus leschenaultii (Geklkonidae), in the Bonai Forest Division, Odisha, India
}

\begin{abstract}
Anil Kumar Jena ${ }^{1}$, Ritesh Suvankar Sahoo ${ }^{1}$, Suraj Kumar Swain ${ }^{1}$, Satyaranjan Behera ${ }^{1}$, Prasad Kumar Dash ${ }^{1}$, Shubhransu Nayak ${ }^{1}$, and Sanat Kumar ${ }^{2}$
\end{abstract}

1'Odisha Biodiversity Board, Bhubaneswar, Odisha 751015, India (kumaranil.deb@gmail.com)

${ }^{2}$ Forest, Environment and Climate Change Department, Government of Odisha, Bhubaneswar, Odisha, India

$\mathrm{T}$ he Ornate Flying Snake (Chrysopelea ornata), which glides from higher to lower levels in the forest canopy (Socha 2011), feeds on fish, frogs, geckos and other small lizards, small snakes, and small birds, bats, and rodents (Grossmann 1999; Das 2010; Hasan et al. 2014; Dutta 2015; Melvinselvan and Nibedita 2016; Babu et al. 2018; Ahmed et al. 2020). The Indian Bark Gecko (Hemidactylus leschenaultii) exploits a wide variety of habitats, including trees, caves, rock clefts, and houses, frequently basking during the day (Dutta et al. 2009).

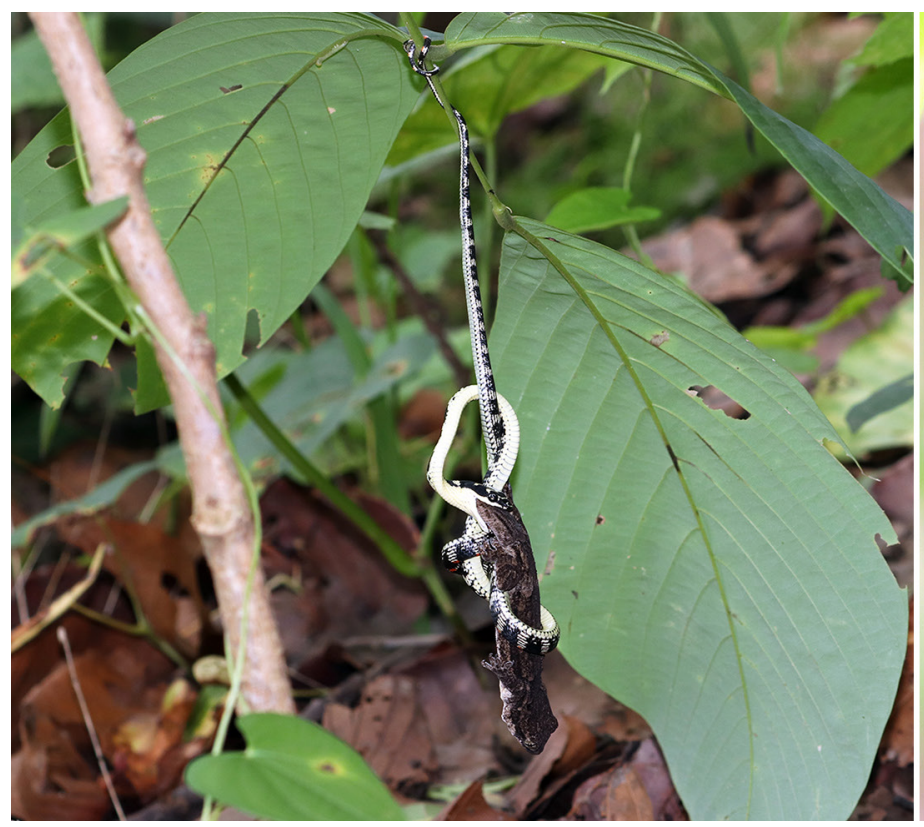

During an inventory of biodiversity in the Bonai Forest Division in Sundargarh District of Odisha in eastern India $\left(21.5055^{\circ} \mathrm{N}, 85.0852^{\circ} \mathrm{E}\right.$; elev. $903 \mathrm{~m}$ asl $)$, we observed predation of an Indian Bark Gecko by an Ornate Flying Snake. At 1259 h on 7 August 2021, we saw a subadult C. ornata falling from about $11 \mathrm{~m}$ high in a Sal Tree (Shorea robusta) and landing with its tail coiled around a branch of a Crocodile Bark Tree (Terminalia elliptica) about $0.3 \mathrm{~m}$ above the ground. A closer examination revealed that it was holding an Indian Bark Gecko by the tail and had immobilized it with several

Fig. 1. An Ornate Flying Snake (Chrysopelea ornata) preying on an Indian Bark Gecko (Hemidactylus leschenaultii) in the Bonai Forest Division, Sundargarh District, Odisha, India. Photographs by Anil Kumar Jena. 
loops of its body. The snake started swallowing the gecko tailfirst and complete ingestion took $40 \mathrm{~min}$. To the best of our knowledge, this is the first record of an Ornate Flying Snake preying on an Indian Bark Gecko.

\section{Acknowledgements}

We thank the DFO, Bonai, for providing financial assistance to execute the research project on the Biodiversity of Bonai Forest Division under the site-specific wildlife management plan. The Chairman and Member Secretary, Odisha Biodiversity Board, provided support and coordination during the study.

\section{Literature Cited}

Ahmed, T., S. Hasan, and H. Naher. 2020. Predation of Common Tree Frog by Ornate Flying Snake at Satchari National Park, Bangladesh. The Himalayan Naturalist 3: 34-35.
Babu, M.Q., T.R. Shihan, R. Debbarma, and P. Debbarma. 2018. Chrysopelea ornata (Ornate Flying Snake). Diet. Herpetological Review 49: 544-545.

Das, I. 2010. A Field Guide to the Reptiles of South-east Asia. New Holland Publishers Ltd., London, UK.

Dutta, S.K. 2015. First locality record of Chrysopelea ornata Shaw, 1802 Golden Tree or Gliding Snake from Kanger Valley National Park, District-Bastar, Chhattisgarh. Biolife 3: 851-853. https://doi.org/10.17812/blj.2015.3415.

Dutta, S.K., M.V. Nair, P.P. Mohaptra, and A.K. Mohapatra. 2009. Amphibians and Reptiles of Similipal Biosphere Reserve. Regional Plant Resource Center, Bhubaneswar, Orissa, India.

Grossmann, W. 1999. Große Echsen als Beute der Schmuckbaumschlange Chrysopelea ornate ornatissima Werner, 1925. Sauria 21(3): 3-6.

Hasan, M.K., M.M.H. Khan, and M.M. Feeroz. 2014. Amphibians and Reptiles of Bangladesh. A Field Guide. Arannayk Foundation, Dhaka, Bangladesh.

Melvinselvan, G. and D. Nibedita. 2016. An observation on fish predation by Ornate Flying Snake, Chrysopelea ornata Shaw 1802 (Serpentes: Colubridae), from southern Western Ghats, Tamil Nadu, India. Russian Journal of Herpetology 23: 311-314.

Socha, J.J. 2011. Gliding flight in Chrysopelea: Turning a snake into a wing. Integrative \& Comparative Biology 51: 969-982. https://doi.org/10.1093/icb/ icr092. 